Journal of Social Sciences 4 (2): 80-87, 2008

ISSN 1549-3652

(C) 2008 Science Publications

\title{
Effect of Infrastructure Development on Income Generation: A Study on Jamuna Bridge Project in Bangladesh
}

\author{
Shaikh Moniruzzaman \\ Department of International Development, International University of Japan, Japan
}

\begin{abstract}
This research is an attempt to examine the impact of infrastructure development on income generation in the north eastern region of Bangladesh which enjoyed a wide range of amenities after the construction of Jamuna Bridge in 1998. The application of 'difference in difference estimator' using the pooled household level income data of the treatment and control area in the pre and post time period of the project is the methodology of this research. The 4 districts situated nearer to the project location at the North eastern region of Bangladesh have been regarded as treatment area while the 4 districts of the Barisal division, the southern part of the country have been treated as control area. The household data of 1995 and 2005 have been used in this research. Regression models using dummy variables, interaction terms and some control variables-land, household size and age exhibit that the infrastructure impact on income of the project area ranges from 7.7-10\% with statistical significance in the 1995-2005. The positive and decreasing rate of impact of control variables on income going in tune with the postulation of positive and diminishing marginal productivity of capital and labor in the production function has made the regression estimations more realistic and spontaneous.
\end{abstract}

Key words: Difference in difference estimator, interaction variables, control variables

\section{INTRODUCTION}

Infrastructure development which is critical for the economic development of any country provides the easier and quicker access of the poor people to the market mechanism. Studies show that infrastructure investments complemented by policy and institutional reforms enable markets to develop and function efficiently, thereby mainstreaming the poor. Infrastructure development contributes both directly and indirectly, to poverty reduction having access to more income generating activities ${ }^{[1]}$. Since the infrastructure investment has been done mainly by the government and in some cases under governmentprivate sector collaboration, this sort of investment can be broadly termed as public capital investment. This public capital investment encompasses the investment in highways, water, sewerage system, bridge construction and other forms of public capital. Private sectors are gradually coming forward to invest for infrastructure investment and since 1990, more than 120 developing countries have invited the private sector to participate in the provision of private infrastructure services $^{[2]}$. Designing infrastructure to deliver services to poor people is a key measure to eradicate poverty ${ }^{[3]}$. Therefore, public capital investment is used to play a significant role in the market mechanism in various ways which ultimately encourage the poor people to participate actively in the income generating activities.

The Jamuna multipurpose bridge project, which is the ever largest physical infrastructure project in Bangladesh, is supposed to work as an aide to foster the economic development of the North eastern region, the main catchments of the project since its opening up in 1998. The objective of the research is to examine the development of the catchments of the project through income generation using the household level income data in the pre and post time period of this facility.

\section{INFRASTRUCTURE AND DEVELOPMENT}

Infrastructure is so pervasive and multidimensional concept that can hardly be well-defined in few words. The publication of 'America in Ruins' by Choate and Walter in 1983, which focused on the nations infrastructure crisis, caused by decades of inadequate investment and poor maintenance of public works, made the word 'Infrastructure' prominent. Infrastructure is generally defined as structural elements that provide the framework supporting an entire structure $^{[4]}$. The term carries multiple meanings in different fields, but is perhaps most widely understood

Corresponding Author: Shaikh Moniruzzaman, Flat No. 2 Takasakiya Annex.1Urasa 4625, Minami Uonuma Shi, Niigata 949-7277, Japan Tel: 81-050-1300-2769, 81-08066-539443 
to refer to roads, airports and utilities. Infrastructure can be categorized as physical and social infrastructure. Education, health and other services are regarded as social infrastructure while roads, airports, bridges, railways as physical infrastructure. It is really hard to envisage all dimensions of infrastructure in one research. Therefore, for the convenience of the research, the definition of infrastructure has been dwindled to only physical infrastructure.

A good number of empirical works on physical infrastructure have been done using broadly two types: Time series estimates of an aggregate production function and cross sectional estimates using state and regional data. Exploration of productivity enhancement due to public infrastructure investment using the time series estimation of an aggregate production function can be done using the concept of the prevalent Solow type growth models focusing that production function incorporates capital and labor inputs with technology. Production process also involves supporting infrastructure services which can be categorized as a component of capital stock. The estimation using the annual data of Canada from 1946-1991 indicates that the marginal product of infrastructure was estimated to be slightly larger than that of direct capital in goods sector, at 0.248 and 0.213 respectively ${ }^{[4]}$. Estimation results from using the 1949-1985 annual U.S. data show that $1 \%$ increase in public infrastructure capital has led to increase the private business sector by $0.36 \%$, ceteris paribus $^{[5]}$. Another estimation from 1949-1987 annual data for the US private non-farm business sector has got the results that the estimated parameter on $\ln \mathrm{K}_{\mathrm{i}}$ is 0.31 , very close to the result reported by Aschauer ${ }^{[6]}$. The study about infrastructure-GDP interactions using the cross country data noted, the contribution of infrastructure services to GDP is substantial and in general exceeds the cost of provision of those services $^{[7]}$. The case of Nepal suggests that establishment of extensive road access to market would confer substantial benefit on average, much of these going to poor households ${ }^{[8]}$. The study on the effects of public infrastructure capital on output supply and input demands in 12 OECD countries, find that in all 12 countries, public capital has positive long-run effects on both output supply and input demands and its mean short run rates of return are fairly low, while corresponding long run rates are much higher but declining over time ${ }^{[9]}$. The estimation results using the US data from 1953-1989 found, when growth in roads changes, productivity growth changes disproportionately in US industries with more vehicles $^{[10]}$.

Public sector infrastructure capital is expected to have a significant impact on the performance and productivity of the private sector. The coincidence of the decrease in public infrastructure capital formation with the decline in productivity growth in the private business sector of the US and Sweden cases indicate some sort of casualty between them. A study shows that the $4.1 \%$ average annual growth rate of capital stock for public infrastructure in Sweden was associated with $4.7 \%$ annual growth in private business sector in 19601973 while in the USA, it was $4.1 \%$ for public infrastructure and $4.7 \%$ for private business sector in the same time period. Subsequently, the public infrastructure mark with $1.3 \%$ average annual growth rate of capital stock and $3.0 \%$ annual growth in private business sector in 1960-1973 in Sweden while in the USA, it was $1.4 \%$ for public infrastructure and $3.1 \%$ for private business sector in the same time period ${ }^{[11]}$.

The exact quantification of the benefits of a particular physical infrastructure project has been difficult due to the methodological constraint and data unavailability. Traditional estimates of the returns to physical infrastructure investments using the internal rate of return approach are generally so low that the investments do not appear viable. Such approaches have also been criticized for not being able to capture the true distributional benefits to the targeted population, particularly for the poor. The benefit cost approach generally includes the immediate observable benefits figure ignoring the long term and the whole spread of the benefits emanating from a particular project $^{[12]}$. Rural road investments are found to reduce poverty significantly through higher agricultural production, higher wages, lower input and transportation costs and higher output prices in Bangladesh. Rural roads also lead to higher girls' and boys' schooling. Road investments are pro-poor, meaning the gains are proportionately higher for the poor than for the non-poor ${ }^{[13]}$. The burden in manufactured exporters in Uganda by transport costs is considerably more significant than the costs imposed by the system of import tariffs. Because of the high transport costs in exporting goods by Uganda, the value addition is $30 \%$ less than it would be if there were no transport costs ${ }^{[14]}$. All these studies unanimously reflect the positive role of infrastructure on development through different channels.

\section{JAMUNA BRIDGE PROJECT AND SOME IMPACTS}

The Jamuna, one of the largest rivers in Bangladesh, has been flowing from North to South through Bangladesh and has divided the country into the east and west. Before the construction of this bridge, ferries which were the only means of crossing 
the river were operated on upstream and downstream of the bridge area. The operation of ferries was greatly influenced by the weather and a one-way trip took more than 2 hours. Moreover, expansion and improvement of the existing ferry facilities was very difficult as the water level and width of the river changed frequently between the dry and rainy seasons. The river Jamuna put a hindrance in the transportation of agricultural products grown in the west to the consumption centers like the major cities-Dhaka and Chittagong in the east. Moreover, western regions were deprived of gas, electricity and communications, which were available in eastern Bangladesh. All these circumstances urged to make a plan to construct a bridge across the river Jamuna. The bridge is located on the Asian Highway and the Trans-Asian Railway which, when fully developed, will provide uninterrupted international road and railway links from South-east Asia to North-west Europe.

The project includes (1) the construction of a multipurpose bridge with four lanes, railways, gas pipeline and power cables (2) construction of $16 \mathrm{~km}$. approach roads on the eastern side and $14 \mathrm{~km}$ on the western side and (3) implementation of river bank protection work for approximately $2.2 \mathrm{~km}$ on both sides. The project was jointly financed by the World Bank, Asian Development Bank and Japan Bank for International Cooperation, each contributing the equivalent of US\$200 million and the remaining US\$96 million was financed by the Government of Bangladesh.

A good number of studies have been conducted by different research organizations and donor agencies to assess the impact of the Jamuna multipurpose bridge project. ADB in 2003 has published an extensive report named Jamuna Bridge Impact Study (JBIS) focusing on the development of the catchments of the project and come up with some positive impact on both rural and urban areas especially in commodity and labor market $^{[15]}$. Table 1 presents the actual and projected annual average daily traffic (AADT) in 1999-2001.

Table 3 shows that the actual amount of light vehicle and bus which has been plying through JB since its inception is more than doubled than the projected amounts. In case of truck movement through the bridge, the actual is less than projected although the gap between them is shrinking over the years.

The establishment of JB has speeded up the labor mobility which ultimately has reduced the wage gap between the labors of the North-west region, the main catchments and the rest of Bangladesh ${ }^{[16]}$. Table 2 presents the changes in daily rural wage rates (in Tk), by activity, gender and region between pre and post JB project.

Table 2 shows that the change of wage in catchments of JB is much higher than the rest of the country. For example, the male labor wage for wet

Table 1: Comparison between actual and projected traffic (AADT) in 1999-2001

\begin{tabular}{|c|c|c|c|c|c|c|}
\hline \multirow[t]{2}{*}{ Year } & \multicolumn{2}{|c|}{ Light vehicle } & \multicolumn{2}{|l|}{ Bus } & \multicolumn{2}{|l|}{ Truck } \\
\hline & Actual & Projected & Actual & Projected & Actual & Projected \\
\hline 1999 & 580 & 227 & 836 & 383 & 903 & 1253 \\
\hline 2000 & 602 & 247 & 1059 & 414 & 1130 & 1364 \\
\hline 2001 & 563 & 268 & 1194 & 446 & 1404 & 1474 \\
\hline
\end{tabular}

Source: Jamuna Bridge Impact Study, ADB, 2003

Table 2: Changes in daily rural wage rates (in Tk*), by activity, gender and region

\begin{tabular}{|c|c|c|c|c|c|c|}
\hline \multirow[b]{2}{*}{ Gender/Activity by season } & \multicolumn{2}{|l|}{$1997-98$} & \multicolumn{2}{|c|}{ 1999-00 } & \multicolumn{2}{|c|}{ (\%) Change } \\
\hline & $\mathrm{ROB} * *$ & North-west & ROB & North-west & ROB & North-west \\
\hline \multicolumn{7}{|l|}{ Male } \\
\hline Aman Transplantation & 51.00 & 37.67 & 52.88 & 49.44 & 3.69 & 31.25 \\
\hline Aman weeding & 42.33 & 32.78 & 49.90 & 40.93 & 17.88 & 24.86 \\
\hline Aman harvest & 60.17 & 45.38 & 65.87 & 61.96 & 9.47 & 36.54 \\
\hline Non-agri, wet season & 68.73 & 47.88 & 67.69 & 60.56 & -1.51 & 26.48 \\
\hline Wet season overall & 59.70 & 44.57 & 65.61 & 61.21 & 9.90 & 37.33 \\
\hline Boro transplantation & 55.22 & 44.75 & 55.43 & 46.94 & 0.38 & 4.89 \\
\hline Boro, weeding & 46.91 & 34.93 & 50.08 & 44.21 & 6.76 & 26.57 \\
\hline Boro, harvest & 65.37 & 57.04 & 75.08 & 65.79 & 14.85 & 15.34 \\
\hline Non-Agri Dry season & 69.92 & 48.52 & 67.54 & 62.25 & -3.40 & 28.30 \\
\hline Dry Season-overall & 64.13 & 46.68 & 65.80 & 59.95 & 2.60 & 28.43 \\
\hline \multicolumn{7}{|l|}{ Female } \\
\hline Aman weeding & 31.00 & 17.27 & 27.50 & 22.69 & -11.29 & 31.38 \\
\hline Non Agri, wet season & 43.33 & 18.75 & 25.00 & 27.50 & -42.30 & 46.67 \\
\hline Wet season-overall & 32.73 & 17.32 & 28.25 & 27.79 & -13.69 & 60.45 \\
\hline Boro weeding & 33.33 & 17.09 & 33.50 & 22.86 & 0.51 & 33.76 \\
\hline Non agri, dry season & 43.33 & 18.75 & 40.00 & 27.14 & -7.69 & 44.75 \\
\hline Dry season-overall & 34.17 & 18.57 & 40.00 & 24.12 & 17.06 & 29.89 \\
\hline
\end{tabular}

Source: BIDS Survey 1997 and 2000. * Currency of Bangladesh, ** Rest of Bangladesh 
season overall category has increased by $37.33 \%$ for the north eastern region in the period 1997-2000 while it has been only $9.9 \%$ for the rest of Bangladesh in the same period. The change of the female labor wage for wet season overall category has experienced a surge by $60.45 \%$ for the north eastern region in the period $1997-$ 2000, but, surprisingly, it has realized a decline by $13.69 \%$ in the rest of Bangladesh in the same period. Therefore, the wage spiral of the catchments of the JB relative to the rest of Bangladesh has been manifest which is supposed to be an advantage of JB project ${ }^{[16]}$.

\section{DATA AND METHODOLOGY}

Selecting the treatment and control group is a vital step for estimating the impact of the physical infrastructure project. There is a confusion regarding the catchments area of JB project as the 17 districts of Rajshahi division on the western side of the country are enjoying more or less the benefits of the project. But for estimating the immediate impact of the JB project, the households of the three nearest districts from the western side- Shirajganj, Bogra and Pabna have been included in the treatment area for this research. The only adjacent district of the eastern side Tangail has also been included in the treatment group since the households dwelling in the eastern side of the district have been enjoying the benefits stemming from the approach road, railways and some other developments done as the components of project works. The detailed literature survey on the infrastructure situation inspires to select the 4 southern districts- Barisal, Bhola, Jhalakathi and Patuakhali as control group. The control and treatment group share some similar propertieslandscape of both of them are fairly plain and there is no visible difference in endowments of households between them. The major diversity between them is that the treatment area has enjoyed the amenities of Jamuna multipurpose bridge while the control has not had the establishment of such big boost up in physical infrastructure situation.

This research requires the household level data of both the treatment and control areas in the pre and post establishment of the JB project. Household Income and Expenditure surveys (HIES) of 1995 and 2005 have been picked up purposefully since the JB has opened up in 1998. The income data in the HIES are nominal in nature. But it will not affect output of the research since we are looking at the difference in income in the period of 1995-2005. Some statistical characteristics like average $\mathrm{HH}$ income, size and age will be found out district wise to analyze the changing situation of the control and treatment areas overtime. The HIES of
Table 3: Number of Households in the treatment and control areas in 1995 and 2005

\begin{tabular}{lcc}
\hline District & 1995 & 2005 \\
\hline Treatment area & 180 & 220 \\
Bogra & 120 & 160 \\
Pabna & 140 & 180 \\
Shirajganj & 160 & 260 \\
Tangail & & \\
Control area & 220 & 180 \\
Barisal & 120 & 140 \\
Bhola & 100 & 120 \\
Jhalakathi & 100 & 140 \\
Patuakhali & &
\end{tabular}

1995 and 2005 contain 7020 and 10080 number of households throughout the whole country ${ }^{[17,18]}$. Number of households of the treatment and control areas for this research has been presented in the Table 3 .

The major scope of the research is to find out the impact of Jamuna multipurpose bridge in terms of income generation, using HIES data of the pre and post establishment of the bridge to compare the pre and post situation between treatment and control group areas. Difference in difference estimator using OLS with pooled cross sectional data across time will be used in the estimation of regression in this research ${ }^{[19]}$. Although the household data that have been used in this research are not exactly cross sectional as the households in both the surveys are not similar, the representative nature of the data in both the surveys has provided the flavor of cross section. Although the income data in the HIES are nominal in nature, it will not affect the output of the research since we have used log of income as dependant variable.

The difference in difference estimator can be estimated by the following Eq.:

$$
\mathrm{I}=\alpha_{0}+\alpha_{1} \mathrm{Yr}+\alpha_{2} \mathrm{PI}+\alpha_{3} \mathrm{Yr} * \mathrm{PI}+\varepsilon_{1}
$$

where, 'I' represents the household income of 2005 and 1995 of both the control and treatment groups; Yr (Year) $=1$ if the income comes from 2005 and 0 otherwise and PI (Physical Infrastructure) $=1$ if the income is from treatment group and 0 otherwise. The parameter of the interaction term Yr* PI, $\alpha_{3}$ measures the impact of the infrastructure project on the household income in the treatment area compared to that of the control areas over the time period from 1995 to 2005. The intercept $\alpha_{0}$ is the average household income in the control group in the initial year, 1995 while the parameter $\alpha_{1}$ captures the change in household income in both treatment and control group from 1995 to 2005 . The coefficient on PI, $\alpha_{2}$ measures the location 
(treatment) effect on income that is not due to the presence of the infrastructure project.

To capture the change in income in percent, the regression equation can be estimated using the log values of the income instead of income as the dependent variable in the following manner:

$$
\log (\mathrm{I})=\beta_{0}+\beta_{1} \mathrm{Yr}+\beta_{2} \mathrm{PI}+\beta_{3} \mathrm{Yr} * \mathrm{PI}+\varepsilon_{2}
$$

where $\beta_{3}$, the coefficient of the interaction term Yr*PI in Eq. (2) represents the impact of infrastructure on income in the treatment areas in percentage form. For the convenience of the analysis of the estimation results, we have used log (I) as dependent variable throughout the whole estimation.

Total operating land (consisting of house and cultivable land), household size and mean household age can be used as control variables to isolate the impact of physical infrastructure on income. To check the individual impact of the control variables on income, the regression of land, $\mathrm{HH}$ size and age on log of income has also been done in this research. To see the change in impact of the physical infrastructure through the coefficient of the interaction term, Yr* PI on income after including the control variables, the following regression can be done:

$$
\log (\mathrm{I})=\delta_{0}+\delta_{1} \mathrm{Yr}+\delta_{2} \mathrm{PI}+\delta_{3} \mathrm{Yr} * \mathrm{PI}+\delta_{4 \mathrm{ij}} \sum \mathrm{C}_{\mathrm{ij}}+\varepsilon_{3}
$$

To capture the opportunity of getting the rate of changes of the contribution of the control variables on income, the regression of Eq. (4) can be performed in this research in the following way:

$$
\begin{aligned}
\log (\mathrm{I})= & \lambda_{0}+\lambda_{1} \mathrm{Yr}+\lambda_{2} \mathrm{PI}+\lambda_{3} \mathrm{Yr} * \mathrm{PI} \\
& +\lambda_{4 \mathrm{ij}} \sum \mathrm{C}_{\mathrm{ij}}+\lambda_{5 \mathrm{ij}} \sum \mathrm{C}_{\mathrm{ij}}^{2}+\varepsilon_{4}
\end{aligned}
$$

The interactions between control and dummy variables will provide the time and location effects of the contribution of the control variables on income. The coefficient of $\mathrm{C}_{\mathrm{ij}}$ *PI will provide the location impact and that of $\mathrm{C}_{\mathrm{ij}} * \mathrm{Yr}$ will give us the time effect of that particular control variable. The regression model of Eq. (5) will capture this time and location effect.

$$
\begin{aligned}
\log (\mathrm{I})= & \eta_{0}+\eta_{1} \mathrm{Yr}+\eta_{2} \mathrm{PI}+\eta_{3} \mathrm{Yr} * \mathrm{PI} \\
& +\eta_{4 \mathrm{ij}} \sum \mathrm{C}_{\mathrm{ij}}+\eta_{5 \mathrm{ij}} \sum \mathrm{C}_{\mathrm{ij}}{ }^{2}+\eta_{6 \mathrm{ij}} \\
& \sum \mathrm{C}_{\mathrm{ij}} * \mathrm{Yr}+\eta_{7 \mathrm{ij}} \sum \mathrm{C}_{\mathrm{ij}} * \mathrm{PI}+\varepsilon_{5}
\end{aligned}
$$

The regression operation through including the different interaction terms in different equation will provide an opportunity to see how the different regressions have responses to the standard error of the interactions $\mathrm{Yr} * \mathrm{PI}$.

\section{ESTIMATION RESULTS}

This chapter will present the estimation results, analysis and the findings stemming from 6 econometric models which have been portrayed in the Table 4 .

The estimation results of model 1 captures the most important effect of interaction factors, $\mathrm{PI} * \mathrm{Yr}$ on income which amounts to 0.077 indicating that $7.7 \%$ increase in income of the households of the treatment area over the period 1995-2005 is attributed to the infrastructure development project and this increase is statistically significant at $1 \%$ level. The household income of both treatment and control in 2005 has experienced an increase by $19.2 \%$ which is represented by the coefficient 0.192 of $\mathrm{Yr}$ and this is also statistically significant at $1 \%$ level. The coefficient of PI in model 1 , which measures the location effect in the treatment area considering the income data of 1995 and 2005 that is not due to the presence of the project is -0.028 indicating the household income in the treatment area decreases by $2.8 \%$ over the control area. But this is not statistically significant.

Model 2, the mere expansion of model 1 with the district dummies, does not change the coefficient of the interaction terms Yr*PI and its standard error. The average hh income of Bogra and Pabna is $0.4 \%$ and $0.5 \%$ lower than that of the base district, Patuakhali respectively. But both of them are not statistically significant. The district Tangail has $0.5 \%$ higher and Barisal $0.4 \%$ lower income than the base district. But those are not statistically significant. Bhola has $8.4 \%$ higher income than the base district which is statistically significant at $1 \%$ level. Jhalakathi district has $6.9 \%$ lower income than the base district that is also statistically significant at 5\% level.

Model 3 includes only the control variables to check their individual impacts on household income. The contribution of the three control variables- amount of land owned by the household, household size and mean age of the household on income is positive statistically significant that implies the relevance of the control variables used in this research. The coefficient of land, 0.038 indicates that one acre additional land owned by the household will lead to increase the income by $3.8 \%$. Similarly, the coefficient of hhs, 0.035 
Table 4: Estimation results

\begin{tabular}{|c|c|c|c|c|c|c|}
\hline \multirow[b]{2}{*}{ Variable } & \multirow[b]{2}{*}{ Model 1} & \multirow[b]{2}{*}{ Model 2} & \multirow[b]{2}{*}{ Model 3} & \multirow[b]{2}{*}{ Model 4} & \multicolumn{2}{|c|}{ Dependent Variable: Log (I) } \\
\hline & & & & & Model 5 & Model 6 \\
\hline constant & $4.599 *(0.014)$ & $4.595^{*}(0.025)$ & $4.466 *(0.028)$ & $4.339 *(0.029)$ & $4.183 *(0.047)$ & $3.979 *(0.052)$ \\
\hline Yr & $0.192 *(0.020)$ & $0.192 *(0.020)$ & & $0.204 *(0.019)$ & $0.198 *(0.019)$ & $0.524 *(0.035)$ \\
\hline PI & $-0.028(0.020)$ & $-0.022(0.032)$ & & $-0.016(0.019)$ & $-0.021(0.018)$ & $-0.051(0.035)$ \\
\hline PI_Yr & $0.077 *(0.027)$ & $0.077 *(0.027)$ & & $0.094 *(0.025)$ & $0.100 *(0.025)$ & $0.082 *(0.024)$ \\
\hline Bogra & & $-0.004(0.025)$ & & & & \\
\hline Pabna & & $-0.005(0.027)$ & & & & \\
\hline Tangail & & $0.005(0.025)$ & & & & \\
\hline Barisal & & $-0.004(0.028)$ & & & & \\
\hline Bhola & & $0.084 *(0.030)$ & & & & \\
\hline Jhalakathi & & $-0.069 * *(0.031)$ & & & & \\
\hline land & & & $0.038 *(0.003)$ & $0.041 *(0.003)$ & $0.072 *(0.005)$ & $0.020 *(0.008)$ \\
\hline hhs & & & $0.035 *(0.003)$ & $0.039 *(0.003)$ & $0.050 *(0.010)$ & $0.096 *(0.011)$ \\
\hline mage & & & $.0015 * *(0.0006)$ & $0.0002(0.0005)$ & $0.008 *(0.002)$ & $0.010 *(0.002)$ \\
\hline land $^{2}$ & & & & & $-0.001 *(0.001)$ & $-0.001 *(0.0003)$ \\
\hline $\mathrm{hhs}^{2}$ & & & & & $-0.001(0.0007)$ & $-0.002 *(0.001)$ \\
\hline mage $^{2}$ & & & & & $-0.0001 *(0.00003)$ & $-0.0001 * 0.00003$ \\
\hline Yr*land & & & & & & $0.040 *(0.006)$ \\
\hline PI*land & & & & & & $0.034 *(0.008)$ \\
\hline Yr*hhs & & & & & & $-0.070 *(0.006)$ \\
\hline PI*hhs & & & & & & $0.002 * * *(0.006)$ \\
\hline $\mathrm{R}^{2}$ & 0.11 & 0.12 & 0.09 & 0.23 & 0.25 & 0.30 \\
\hline Observation & 2540 & 2540 & 2540 & 2540 & 2540 & 2540 \\
\hline
\end{tabular}

implies that one person increase in hh will lead to increase the income by $3.5 \%$ while contribution of age to income is only $0.015 \%$. But all these contributions are average results found in the period 1995-2005 since they are from the income data of both 1995 and 2005.

Model 4 which literally includes the interaction term PI*Yr and dummy variables of the model 1 and control variables of model 3 increases the specification of the interaction term Yr*PI. After including the controls, the coefficient of $\mathrm{Yr} * \mathrm{PI}$ increases from 0.077 in model 1 to 0.094 in model 4 implying that when the impact of the three variables-land, hhs and mage on household income are controlled, $9.4 \%$ increase in income in the treatment area is attributable to the infrastructure development project. This also yields a smaller standard error for the interaction terms, 0.025 , which was 0.027 in model 1 . Both the dummy variables Yr and PI have less standard error in model 3 than those of model 1. The low value of correlation, 0.19 between hhs and owned land, -0.32 between hhs and mage and -0.012 between land and mage repels the potential problem of multicollinearity from the model. In this model, the contribution of land and hhs to income has increased to $4.1 \%$ and $3.9 \%$ respectively compared to those of model 3 keeping the same standard error while age has had lower contribution $(0.02 \%)$ which is not statistically significant.

The estimation results of Model 5 produce higher value $(0.100)$ for the coefficient of Yr*PI and lower standard error compared to model 4 . The coefficients of the square of land and hhs are fairly equal at -0.001 which implies that the increase of land by one acre and hhs by one person will reduce the rate of increase in income by $0.1 \%$. Although the rate is very meager in amount, it is significant at $1 \%$ level of significance in case of land while the coefficient of the $\mathrm{hhs}^{2}$ is not statistically significant. The coefficient of the square of the mage is even smaller, -0.0001 , still, it is statistically significant at $1 \%$ level of significance. All the square of the control variables have negative coefficient in model 5 which go in tune with the theory of diminishing marginal returns.

Model 6 adds the new interaction terms between dummy variables ( $\mathrm{Yr}$ and $\mathrm{PI}$ ) and control variables (land and hhs) to capture the time and treatment (location) effects of the contribution of land and hhs on income. The mean age has been excluded from the model as its contribution to income is very less in amount. The incorporation of these new interaction terms has reduced the coefficient of $\mathrm{Yr} * \mathrm{PI}$ to 0.084 from 0.100 in model 5 and the corresponding standard error has also become smaller (0.024) from 0.025 in model 5. The coefficient of $\mathrm{Yr}^{*}$ land represents the changes in the contribution of land in 2005 compared to 1995 , which is 0.020 or $2.00 \%$, with $1 \%$ level of significance and the coefficient of $\mathrm{Yr} * \mathrm{hhs}$, the changing contribution of hhs in 2005 is 0.070 or $7.0 \%$ with $1 \%$ level of significance. The time effect of the contribution of land, which captures the total contribution of land to income in 2005 compared to 1995 is 0.06 (0.02, the 
coefficient of land +0.04 , the coefficient of Yr*land). The same effect of the contribution of hhs, which represents the total contribution of hhs to income in 2005 compared to 1995 is $0.026(0.096$, the coefficient of hhs $+(-0.070)$, the coefficient of Yr*hhs). The coefficient of PI*land which represents the changes in the contribution of land in the treatment area compared to the control area in the time period of 1995-2005, is 0.034 or $3.4 \%$ with $1 \%$ level of significance and the coefficient of PI*hhs, the changing contribution of hhs is 0.002 or $0.2 \%$ with $10 \%$ level of significance. The location effect of the contribution of land, representing the total contribution of land to income in the treatment area compared to the control area in the time period of $1995-2005$ is $0.054(0.02$, the coefficient of PI+0.034, the coefficient of PI*land). The same effect of the contribution of hhs, indicating the total contribution of hhs to income in the treatment area compared to control area is 0.098 (0.096, the coefficient of hhs +0.002 , the coefficient of $\mathrm{PI} * \mathrm{hhs}$ ).

Findings from the estimation results: The coefficient of interaction terms, Yr*PI which represents the infrastructure impact on income of the project area ranges from $7.7-10 \%$ in different models in this research and the coefficient values of $\mathrm{Yr} * \mathrm{PI}$ in all the models are statistically significant at $1 \%$ level of significance. All the control variables- land, household size and average age of the household which are poorly correlated, have positive impact on income which are statistically significant as well. The incorporation of the control variables has increased the coefficient value of interaction terms, Yr*PI which implies that after controlling the impact of the control variables on income, the effect of infrastructure project on income has been more. Moreover, the incorporation of the control variables has reduced standard error of the coefficient value of interaction terms, Yr*PI, which implies that after controlling the impact of the control variables on income, the effect of infrastructure project on income has been more specified and statistically significant. All the square of control variables- land, household size and average age of the household have negative value indicating the theory of diminishing returns.

The positive value (0.040) of the change in contribution of land indicates that land has become more productive in both the treatment and control areas in 2005 compared to 1995 which is supported by the prevalence of increasing cropping intensity trend in the country. Similarly, the negative value $(-0.070)$ of the change in contribution of hhs to income in 2005 compared to 1995 implies that small family size has become more productive in terms of income generation in both the treatment and control areas in 2005. This finding goes in line with the inverted $U$ curve relationship between population size and development. On the other hand, the positive value of the location effect of the contribution of land (3.4\%), which is grasped by the coefficient of PI*land, indicates that the lands in the treatment area are generating more income than those of the control areas. Similarly the positive value of the location effect of the contribution of hhs, represented by the coefficient of PI*hhs, implies that households in the treatment area are more productive than those of the controls in the time period of 19952005. Therefore, the lands have been more productive and households have become more efficient in the treatment areas compared to control areas in the postulated time period in our research.

\section{CONCLUSION}

This research ensures the contribution of physical infrastructure for acceleration of income generation which has been manifested in the catchments of Jamuna Multipurpose Bridge project through the regression analysis. Incorporation of the control variables has increased the preciseness of the impact of physical infrastructure on income generation. The important stronghold of this research is that the data used for this analysis is not collected for studying physical infrastructure impact. Selection of control areas is another important dimension to influence the estimation results. For this reason, the region with maintaining backward physical infrastructure for the study period has been sought out to be taken as control area. The control areas have also enjoyed some physical infrastructure developments which are not as remarkable as the JB project.

The major risk of this research is that the households of the two surveys are not same. Although HIES guarantees that the household under the surveys are quite representative in nature, still there is a risk of the existence of any structural difference between the households in these two surveys, in that case, the estimation results will come out with some bias. This structural difference can accrue from income difference, household size, land ownership etc. Another risk is that we have not controlled the social safety net programs in the two areas which is also a limitation of this research. Although the benefits of the social safety net programs have been included in the income data, the trend of social safety net program in the both control and treatment areas need to controlled to have more specific physical infrastructure impact. 
In spite of all these potential risks and limitation of this research, it can be said that the outcome of the research which signifies the acceleration of income generation attributable to the physical infrastructure project through making the factors of production more efficient, has again fortified the idea that public capital investment has fostered the private income generation.

\section{REFERENCES}

1. Fan, S., 2004. Infrastructure and pro-poor growth. In: A Paper Prepared for the OECD DACT POVNET Agriculture and Pro-poor Growth, Helsinki Workshop, 17-18 June 2004.

2. Estache A.; Foster, V. and Wodon, Q., 2001. Making infrastructure reform work for the poor. In: Policy Options Based on Latin American Experience. A World Bank Institute Study presented in the conference in Rio di Janeiro in September 2001.

3. World Bank, 2002. World Development Report. Washinton DC.

4. Wylie, Peter J., 1996. Infrastructure and canadian economic growth 1946-1991. Can. J. Econ., 29 (Special Issue:Part 1): 350-355.

5. Aschauer, David A., 1989. Is public expenditure productive? J. Monetary Econ., 23: 177-200.

6. Munnell, Alicia H., 1990. How does public infrastructure affect regional economic performance? N. Engl. Econ. Rev., Jan/Feb :11-32.

7. Hadi, E. and Ramirez, Teresa M., 2002. Institutions, infrastructure and economic growth. J. Dev. Econ., 70: 443-77.

8. Jacoby, Hanan G., 2000. Access to markets and the benefits of rural roads. Econ. J., 110 (465): 713-737.

9. Panicos, Demetriades O. and Theofanis, Mamuneas P., 2000. Intertemporal output and employment effects of public infrastructure capital: Evidence from 12 OECD economies. Econ. J., 110 (465): 687-712.
10. Fernald, John G., 1999. Roads to Prosperity? Assessing the Link between Public Capital and Productivity. The American Economic Review, 89(3): 619-638.

11. Ernst, Berndt R. and Hansson, B., 1992. Measuring the contribution of public infrastructure capital in sweden. Scandinavian J. Econ., 94 (Supplement Proceedings of a Symposium on Productivity Concepts and Measurement Problems: Welfare, Quality and Productivity in the Service Industries): S151-S168.

12. Ahmed, R. and M. Hossain, 1990. Development Impact of Rural Infrastructure in Bangladesh. International Food Policy Research Institute Research Report, No. 83, Washington, DC.

13. Shahidur R. Khandker; Zaid Bakht and Gayatri B. Koolwal, 2007. The Poverty Impact of Rural Roads: Evidence from Bangladesh. A WB study in Bangladesh, Dhaka.

14. African Development Bank, 1999. African Development Report, Abidjan.

15. Asian Development Bank, 2003. Jamuna Bridge Impact Study, Dhaka.

16. Bangladesh Institute of Development Studies, 2004. Poverty Impact of Rural Roads and Markets Improvement and Maintenance Project of Bangladesh. Mimeo.

17. Bangladesh Bureau of Statistics, 1995. Household Income and Expenditure Survey, Dhaka.

18. Bangladesh Bureau of Statistics, 2005. Household Income and Expenditure Survey, Dhaka.

19. Wooldridge Jeffrey M., 2006. Introductory Econometrics: A Modern Approach. Thomson South-western, pp: 448-460. 